\title{
Mechanism of herbal medicine on hypertensive nephropathy (Review)
}

\author{
ZHAOCHENG DONG ${ }^{1,2}$, HAORAN DAI ${ }^{3}$, ZHANDONG FENG $^{4}$, WENBIN LIU $^{2,5}$, YU GAO $^{2,5}$, \\ FEI LIU ${ }^{1,2}$, ZIHAN ZHANG ${ }^{1,2}$, NA ZHANG $^{2,5}$, XUAN DONG $^{2,5}$, QIHAN ZHAO ${ }^{2,5}$, \\ XIAOSHAN ZHOU ${ }^{1}$, JIELI DU ${ }^{1}$ and BAOLI LIU ${ }^{2}$
}

\author{
${ }^{1}$ Beijing Hospital of Traditional Chinese Medicine, Beijing University of Chinese Medicine, Beijing 100029; \\ ${ }^{2}$ Beijing Hospital of Traditional Chinese Medicine Affiliated to Capital Medical University, Beijing 100010; ${ }^{3}$ Shunyi Branch, \\ Beijing Traditional Chinese Medicine Hospital, Beijing 101300; ${ }^{4}$ Beijing Chinese Medicine Hospital Pinggu Hospital, \\ Beijing 101200; ${ }^{5}$ Beijing Hospital of Traditional Chinese Medicine, Capital Medical University, Beijing 100069, P.R. China
}

Received September 2, 2020; Accepted December 30, 2020

DOI: $10.3892 / \mathrm{mmr} .2021 .11873$

\begin{abstract}
Hypertensive nephropathy is the most common complication of hypertension, and is one of the main causes of end-stage renal disease (ESRD) in numerous countries. The basic pathological feature of hypertensive nephropathy is arteriolosclerosis followed by renal parenchymal damage. The etiology of this disease is complex, and its pathogenesis is mainly associated with renal hemodynamic changes and vascular remodeling. Despite the increased knowledge on the pathogenesis of hypertensive nephropathy, the current clinical treatment methods are still not effective in preventing the development of the disease to ESRD. Herbal medicine, which is used to relieve symptoms, can improve hypertensive nephropathy through multiple targets. Since there are few clinical studies on the treatment of hypertensive nephropathy with herbal medicine, this article aims to review the progress on the basic research on the treatment of hypertensive nephropathy with herbal medicine, including regulation of the renin angiotensin system, inhibition of sympathetic excitation, antioxidant stress and anti-inflammatory protection of endothelial cells, and improvement of obesity-associated factors. Herbal medicine with different components plays a synergistic and multi-target role in the treatment of hypertensive nephropathy. The description of the mechanism of herbal medicine in the treatment of hypertensive nephropathy will contribute towards the progress of modern medicine.
\end{abstract}

Correspondence to: Dr Baoli Liu, Beijing Hospital of Traditional Chinese Medicine Affiliated to Capital Medical University, 23 Meishuguanhou Street, Dongcheng, Beijing 100010, P.R. China E-mail: liubaoli@bjzhongyi.com

Key words: hypertensive nephropathy, herbal medicine, vascular remodeling, endothelial cells, renin angiotensin system

\section{Contents}

1. Introduction

2. Pathogenesis of hypertensive nephropathy

3. Mechanism of herbal medicine in the treatment of hypertensive nephropathy

4. Model of hypertensive nephropathy in herbal medicine research

5. Discussion

\section{Introduction}

The association between high blood pressure and the kidney is high $(1,2)$. The kidney participates in the formation of blood pressure through the secretion of renin and the regulation of body fluids (3). The imbalance of such regulation leads to hypertension. In addition, the kidney is one of the important target organs affected by hypertension-associated damage $(4,5)$. The renal tubules are sensitive to ischemia, and dysfunction of distal tubules concentration often occurs first, including increased nocturia, decreased urine-specific gravity and decreased urine osmotic pressure (6). Over time, proteinuria, mostly mild, may occur after glomerular ischemia, while moderate proteinuria may occur in certain patients with high blood pressure $(7,8)$. The decrease in the glomerular filtration rate eventually leads to end-stage renal disease (ESRD). In terms of renal pathology, the kidney size is normal at the early stage, while the kidney volume is decreased at the late stage, and its surface is fine and granular. This is caused by arteriolosclerosis, which leads to renal parenchymal damage and ischemic sclerosis in certain glomeruli (9-11). Ischemic lesions are also found in the renal interstitium and tubules. In terms of treatment, the current therapeutic aim of modern medicine is only to protect the residual nephrons and to delay the progression of renal damage using antihypertensive drugs (2).

Herbal medicine has been historically used in the treatment of hypertensive nephropathy, and its clinical effect is remarkable. Therefore, it is of great clinical and economical importance to explore its mechanism of action. The present 
study aims to review the recent basic research on the mechanism of herbal medicine for the treatment of hypertensive nephropathy.

\section{Pathogenesis of hypertensive nephropathy}

Hypertensive nephropathy is more common in elderly patients $>50$ years of age with a long history of chronic hypertension, and is more prevalent in men compared with women (12). The clinical manifestations appear later than the pathological changes (13). Hypertension usually lasts for $>10$ years before the gradual emergence of nocturia, mild proteinuria and other associated clinical symptoms (14). This disease is usually preceded by distal tubular dysfunction, followed by glomerular dysfunction $(15,16)$. The patient's renal pathology starts with renal arteriopathy, followed by ischemic renal parenchymal damage (11). Renal arteriolosclerosis mainly affects the arterioles before the glomerulus, including hyaline degeneration of the glomerular arterioles, and thickening of the medium membrane of the interlobular and arcuate arteries $(17,18)$. The reason for this is vascular endothelial damage and increased vascular cavity pressure, which results in the subcutaneous accumulation of plasma components $(19,20)$. Hypertrophy and hyperplasia of membranous smooth muscle cells in the interlobular and arcuate arteries are accompanied by different degrees of intimal fibrosis (21). Both lesions lead to hardening and thickening of the arteriole walls, narrowing of the lumen and decreased renal blood supply, followed by ischemic renal parenchymal damage (22-24). As arteriopathy progresses, the glomerulus first undergo ischemic shrinkage, namely capillary basement membrane wrinkling, while the lumen remains open. Next, ischemic sclerosis occurs, where the basement membrane is highly wrinkled and the capillary lumen collapses $(25,26)$. The renal tubules and interstitium are also ischemic, including tubules atrophy, thickening of the basement membrane, interstitial fibrosis and limited mononuclear cell infiltration $(27,28)$. When parts of the glomeruli are damaged, the remaining glomeruli compensatively enhance the discharge of metabolic waste substances, eventually leading to glomerulosclerosis.

The mechanisms of hypertensive nephropathy is mainly renal hemodynamic changes and vascular remodeling caused by hypertension $(29,30)$. When hypertension occurs, changes in renal hemodynamics will lead to changes in the function and structure of renal arterioles, which is known as vascular remodeling (31). During hypertension, the change in arteriole function is mainly manifested as increased responsiveness to vasoconstrictive substances $(32,33)$, which results in increased vascular resistance and decreased renal plasma flow. However, in previous studies, the renal function remained normal due to increased glomerular filtration fraction. If hypertension persists, it can lead to structural changes in renal arterioles, particularly in the interlobular and arcuate arteries, and to hypertrophy and proliferation of smooth muscle cells $(34,35)$. The mechanism is complex, and is the result of various active substances in the circulation, as well as an imbalance of vascular endothelial synthesis and secretion. For example, endothelin-1 (ET-1) is increased, while nitric oxide (NO) is decreased (36-38). Finally, the renal arteriole wall thickens, the lumen narrows, the vascular compliance decreases, the renal plasma flow further decreases and the renal function is damaged. However, not all the renal arterioles undergo hypertrophic remodeling, resulting in hypoperfusion and ischemic renal parenchymal damage. In fact, the arterioles in the other part of the kidney do not show hypertrophic remodeling, but rather compensatory hyperperfusion (39). The glomeruli, which are supplied by these arteries, also change from exhibiting hypertrophy to exhibiting focal segmental sclerosis (40). Although the purpose of hypertensive nephropathy treatment is to protect the residual nephron and delay the progression of renal damage, the key aim of the treatment is to effectively control blood pressure $(4,9)$. Therefore, the majority of research on the treatment of hypertensive nephropathy focuses on hypertension. Moreover, relevant studies on the control and treatment of hypertensive nephropathy using traditional Chinese medicine via a variety of mechanisms also investigate hypertension (41-43). The basic studies on herbal medicine prescribed for hypertensive nephropathy are shown in Table I.

\section{Mechanism of herbal medicine in the treatment of hypertensive nephropathy}

Suppression of the renin-angiotensin system (RAS). The RAS plays an important role locally in the kidney. Angiotensin II (AngII) can directly bind to angiotensin receptors on renal arteriolar smooth muscle cells and stimulate vascular smooth muscle contraction (44). AngII also stimulates the sympathetic nerve to promote vascular smooth muscle resistance, thus leading to increased renal vascular resistance. In addition, AngII can increase sodium reabsorption through the aldosterone action on distal renal tubules, thus increasing the blood volume and leading to increased blood pressure (45). Numerous basic studies have shown that herbal medicine can play a crucial role in the treatment of hypertensive nephropathy by inhibiting RAS. Genipin, as one of the main components of Gardenia, can protect the renal function of spontaneously hypertensive rat (SHR) via the AngII-TLR/MyD88/mitogen activated protein kinase (MAPK) pathway (46). Qian Yang Yu Yin granules can suppress AngII in multiple manners. The mechanism includes alleviation of SHR and inhibition of 293T cells' effort induced by AngII through the epigenetic pathway associated with nicotinamide $\mathrm{N}$-methyltransferase expression (47). The Jiangya Tongluo formula can regulate the protective effect of adrenomedullin and angiotensin in rats with hypertensive nephrosis (48). The heart-protecting musk pill can decrease the partial levels of AngII in SHR kidney, thus treating hypertensive nephropathy (49).

In addition to studies on hypertensive nephropathy, numerous studies have demonstrated that herbal medicine can show efficacy in the treatment of chronic kidney disease or hypertension by inhibiting the RAS. For example, Chrysanthemum acts as an antihypertensive by acting on the RAS (50). The water extracts of kidney bean sprouts have been demonstrated to inhibit angiotensin converting enzyme, thus exhibiting potential for lowering blood pressure (51). Alisol B 23 acetate, as one of the main ingredients of Rhizoma alismatis, can suppress the expression of constituents of the RAS, and can inhibit the epithelial-to-mesenchymal transition (EMT) in nephrectomised rats, thus lowering blood pressure, decreasing serum creatinine and preventing proteinuria (52). In addition, Alisol B 23 acetate can block the RAS/Wnt/ $\beta$-catenin axis 
Table I. Basic experimental studies on herbal medicine prescriptions.

\begin{tabular}{|c|c|c|c|c|}
\hline Composition & Animal & Cell & Mechanisms & (Refs) \\
\hline $\begin{array}{l}\text { Polygoni Multiflori Radix, Herba Bidentis } \\
\text { Bipinnatae, Corni Fructus }\end{array}$ & - & 293 T cells & $\begin{array}{l}\text { Suppression of renin-angiotensin } \\
\text { system }\end{array}$ & $(44)$ \\
\hline $\begin{array}{l}\text { Scrophulariae Radix, Alismatis Rhizoma, } \\
\text { Cyathulae Radix }\end{array}$ & - & $\begin{array}{l}\text { Human mesangial } \\
\text { cells }\end{array}$ & $\begin{array}{l}\text { Antioxidant stress and } \\
\text { anti-inflammatory responses }\end{array}$ & (89) \\
\hline $\begin{array}{l}\text { Bidens pilosa Linn, Cornus officinalis Sieb. } \\
\text { et Zucc, Fallopia multiflora (Tunb.) Harald., } \\
\text { Scrophu laria ningpoensis Hemsl., Cyathula } \\
\text { officinalis Kuan, Alisma plantago-aquatica Linn. }\end{array}$ & SHR & - & $\begin{array}{l}\text { Antioxidant stress and } \\
\text { anti-inflammatory responses }\end{array}$ & (86) \\
\hline $\begin{array}{l}\text { Nacre, Cassia occidentalis, Safflower, Salvia } \\
\text { miltiorrhiza, Chrysanthemum }\end{array}$ & SHR & - & $\begin{array}{l}\text { Suppression of renin-angiotensin } \\
\text { system }\end{array}$ & $(45)$ \\
\hline $\begin{array}{l}\text { Artificial Mouchus, Cortex Cinnamomi, Calculus } \\
\text { Bovis Artifactus, Styrax, Radix Ginseng, }\end{array}$ & SHR & - & $\begin{array}{l}\text { Suppression of renin-angiotensin } \\
\text { system; antioxidant stress and }\end{array}$ & \\
\hline Syntheticum, Venenum Bufonis & & & $\begin{array}{l}\text { Borneolum anti-inflammatory } \\
\text { responses }\end{array}$ & $(46)$ \\
\hline
\end{tabular}

to improve podocyte injury and the EMT of HK-2 cells (53). Ergone, one of the main ingredients of Polyporus umbellatus, and pachymic acid B, one of the main ingredients of Poria cocos, have the same effect (53). In addition, poricoic acid ZA, ZF, ZG and $\mathrm{ZH}$, which are important components of Poria cocos, inhibit the effect of the RAS to protect podocytes and renal tubular epithelial cells, but affect the RAS and the transforming growth factor- $\beta 1$ (TGF- $\beta 1) / S m a d$ axis $(54,55)$. Previous studies have shown that poricoic acid ZC, ZD and ZE in Poria Cocos protect renal interstitial fibrosis due to unilateral ureteral obstruction in mice via TGF $\beta /$ Smad pathway (56). It has been reported that 25-O-methylalisol F, the main component of Alisma, protects EMT of rat renal proximal tubular epithelial cell lines through this pathway (57). The therapeutic effect of Radix Scrophulariae on SHR can be attributed to the suppression of the RAS through the inhibition of the extracellular regulated protein kinase 1/2, c-Jun N-terminal kinase and p38 MAPK pathways (58). Xin-Ji-Er-Kang can inhibit oxidative stress by affecting the RAS, and can improve renal injury after myocardial infarction in rats (59). In addition, all herbal medicines that contain flavonoids, terpenoids, saponins and alkaloids are able to inhibit the RAS (16). Among them, common herbs containing flavonoids are Scutellaria baicalensis, Flos cmysanthemi, Sambucus adnata wall, bud of Chinese Scholar tree, Equisetum spp, Chrysanthemum indicum L., Chamaecyparis obtusa, Orthosiphon stamineus and Tropaeolum Majus L. (60-62). Common herbs containing terpenoids are the surface layer and sclerotium of Poria cocos, Alismatis rhizome and Polyporus umbellatus $(56,60,63)$. A common herb containing saponins is the ginseng root (64). Common herbs containing alkaloids are Gambirplant, leonurus, Ophora flavescens, S. subprostrata, S. alopecuroides and Uncaria rhynchophylla $(60,65,66)$.

Inhibition of sympathetic excitation. In patients with hypertension, the sympathetic adrenaline system is hyperactive from the central to the arterial walls. The synthesis and release of the neurotransmitter catecholamine increases, thus leading to renal arteriole contraction, and renal vascular resistance increases, thus affecting vascular remodeling $(67,68)$. In addition, the catecholamine released by sympathetic nerves can directly act on proximal renal tubules, and increase sodium reabsorption, blood volume and blood pressure $(69,70)$. Although it has not been demonstrated yet that the mechanism of herbal medicine in the treatment of hypertensive nephropathy involves the regulation of the sympathetic nervous system, numerous herbal medicines have been reported to be able to play a role in the inhibition of sympathetic nervous system in previous basic experiments and clinical trials.

Chrysanthemum plays a role in decreasing blood pressure by inhibiting the sympathetic nerve (50). Radix scrophulariae, by inhibiting sympathetic excitement, suppresses SHR, and ventricular remodeling occurs (58). Astragaloside IV can decrease norepinephrine levels in the blood of high-fat diet-induced obese rats and in kidney tissues, which indirectly demonstrates that Astragaloside IV has the effect of inhibiting sympathetic nerves (71). Guizhi decoction can inhibit the cholinergic transdifferentiation of sympathetic nerves, and improve the anatomical and functional denervation of sympathetic nerves (72). In addition, acupuncture, electroacupuncture and moxibustion can also regulate the sympathetic nervous system, although their mechanism of action is complex (73-75).

Antioxidant stress and anti-inflammatory responses. Oxidative stress is caused by the imbalance of reactive oxygen species (ROS) and the antioxidant mechanism in the body. In hypertensive nephropathy, inflammatory damage is caused by the interaction of various cells such as macrophages and $\mathrm{T}$ lymphocytes, or inflammatory mediators or chemokines $(13,76)$. These inflammatory cells secrete cytokines that can lead to endothelial dysfunction, which can aggravate and even lead to hypertension. Inflammatory reactions and oxidative stress play a common role and cause each other in hypertension-associated renal damage (77). Therefore, anti-oxidative stress and anti-inflammation can play a role in alleviating hypertensive nephropathy.

As the most widely used herb in cardiovascular diseases, Salvia miltiorrhiza can significantly improve SHR blood 
pressure, decrease ROS production and improve vascular remodeling (78). The flower of Coreopsis tinctoria Nutt. is widely used in the treatment of hypertension, diabetes, obesity and other diseases. It exerts anti-inflammatory effects through its antioxidant stress properties and its ability to inhibit tumor necrosis factor- $\alpha$ (TNF- $\alpha$ ), interleukin-6 (IL-6) and nuclear factor- $\kappa \mathrm{B}(\mathrm{NF}-\kappa \mathrm{B})$ (79). Brazilian red propolis could alleviate hypertension and kidney injury in 5/6 renal ablation model rats through antioxidant stress (80). As an extract of Apocynum venetum, its polyphenols can improve the renal index of D-galactose-induced oxidative stress in mouse models (81). Tulbaghia violacea can improve NF- $\mathrm{NB}$ and TGF- $\beta$ expression in Dahl salt-sensitive rat kidneys, and plays a role in lowering blood pressure and protecting renal function (82). Resveratrol, the main component of Veratrum nigrum L., has been demonstrated to have anti-ROS effects, and has the potential to lower blood pressure (83). As the main component of celery seeds, 3-n-butylphthalide plays a protective role in renal tubules through decreased stress, as well as the expression of pro-inflammatory cytokines and TGF- $\beta 1$ in kidney tissues (84). Resveratrol, the main component of Veratrum nigrum L., has been demonstrated to have anti-ROS effects, and has the potential to lower blood pressure (85). Paeonol can effectively improve the blood pressure of spontaneously hypertensive rats, and its mechanism may be associated with reduction of blood viscosity, antioxidant stress and improvement of antioxidant capacity (86). Galangin, as the main extract of Alpinia officinarum hance, inhibits ROS as well as the mRNA expression of prostaglandin-endoperoxide synthase 2, TNF- $\alpha$, IL- $1 \beta$ and IL-18, thus exerting a protective effect in rat renal epithelial cells (87). Icariin, as the main component of Epimedium brevicornu, can decrease the production of ROS by inhibiting the activity of NADPH oxidase, thus reducing the vasoconstriction effect of AngII-induced hypertension in rats (88). Natural antioxidants derived from food and herbal extracts such as tea polyphenols, curcumin and lycopene, have been widely used as complementary therapies to slow the progression of ESRD.

Jiang Ya Yi Shen granules exert their protective role by inhibiting NF- $\mathrm{NB}$ signaling-mediated micro-inflammatory cytokines, including IL-6, TNF- $\alpha$ and intercellular cell adhesion molecule-1 (ICAM-1), on SHR nephropathy (89). Tongxinluo can inhibit the effects of oxidative stress and improve SHR glomerular sclerosis (90). Ban Xia Bai Zhu Tian Ma decoction could inhibit IL-1, IL-6, TNF- $\alpha$ and inducible nitric oxide synthase (NOS) in SHR to improve the heart damage caused by hypertension (91). Qian Yang $\mathrm{Yu}$ Yin granules can also inhibit the influence of AngII on the NADPH oxidase 4-dependent pathway, thereby inhibiting the proliferation of human mesangial cells, and lowering the production of ROS and anti-inflammatory response (92). The heart-protecting musk pill, also called Shexiang Baoxin pill, can decrease TGF- $\beta$ and ICAM-1, thus exerting an anti-inflammatory effect, and can be used to treat SHR nephropathy and to improve vascular remodeling $(49,93)$. Xin-Ji-Er-Kang-induced NOS in high-salt induced hypertensive mice can improve the activity and oxidative stress, and alleviate vascular remodeling (94-96). Qingxuan Jiangya decoction can affect the TGF- $\beta 1 /$ Smad signaling pathway to play a crucial role in improving renal interstitial fibrosis in SHR (97). In a previous study, Shenkang improved renal injury in mice with unilateral ureteral occlusion by acting on the TGF- $\beta /$ Smad3, Sirtuin/forkhead box protein O and B-cell lymphoma-2-associated X protein pathways (98).

Regulation of vasoactive substances and other mechanisms of endothelial cell protection. Hypertension can promote the synthesis of endothelial cells and the secretion of a variety of vasoactive substances. These substances maintain vascular tension and permeability, but can lead to vascular smooth muscle hypertrophy and hyperplasia. The sustained effect of blood pressure on vascular endothelial cells will result in endothelial cell damage $(99,100)$. In addition, the increase in endogenous plasma NO synthase inhibitors in patients affects the decrease in NO synthesis by endothelial cells (101). The increase in ET-1, which can lead to vasoconstriction, eventually leads to enhanced vasoconstriction response and increased renal vascular resistance, and promotes the occurrence of vascular remodeling (37). Therefore, the best indicator of endothelial cell function is observation of the dynamic changes in vasoactive factors such as NO and ET-1.

Cirsium japonicum improves the cardiac effects of renal hypertension in 2-kidney 1-clip rats by increasing serum NO levels (102). Morinda citrifolia can significantly decrease blood pressure and 24-h urinary NO metabolite in SHR, and its juice extract can increase the phosphorylation of endothelial NOS in human umbilical vein endothelial cells, and promote the endothelial vasodilation of the aortic ring and NO products in rats (103). Zingiber officinale var. rubrum exerts a significant vascular relaxation effect in SHR. Its possible mechanism of vasodilatation includes the release of $\mathrm{NO}$ or transmembrane calcium channels (104). Curcumin can protect the renal kidney function of cadmium-induced renal damage in rats, and can play a protective role on renal injury caused by hyperuricemia or high-fructose intake, and one of the mechanisms is to increase the production of NO $(105,106)$. Morin (also known as $3,5,7,2^{\prime}, 4^{\prime}$-pentahydroxyflavone) is widely present in fruits and vegetables such as almond, old fustic, Indian guava and Osage orange. This compound may play a strong role in vascular widening by $\mathrm{NO}$, muscarinic receptors, $\beta 2$-adrenegic receptors and calcium channels (107). Hydroxysafflor yellow A, the principal component of Carthamus tinctorius L., induces angiogenesis in rat mesenteric arteries by transient receptor potential vanilloid 4 (TRPV4) -dependent calcium influx in endothelial cells (108). A large number of clinical experiments showed that sodium tanshinone IIA sulfonate combined with angiotensin receptor blockers (ARBs) had a stronger effect on improving renal function in patients with primary hypertensive nephropathy compared with ARB monotherapy (109). Sodium tanshinone IIA sulfonate, the main ingredient in the herb Salvia miltiorrhiza, has been shown to protect vascular endothelial cells. In addition, the combination of caffeic acid and ferulic acid can dilate blood vessels and resist ET-1, while exerting a hypotensive effect through ester bonds and telmisartan (110). Qingxuan Jiangya decoction can prevent hypertension and improve vascular remodeling in SHR by lowering the serum ET-1 level and inhibiting the TGF- $\beta 1 / \mathrm{Smad}$ pathway (111). 17-Methoxyl-7-hydroxy-furanchalcone, as an active ingredient of Fordia cauliflora, was capable of improving cardiac reconstruction from hypertension in rats 
by regulating the eNOS-NO signaling pathway (112). The combination of Astragalus membranaceus and Salvia miltiorrhiza can improve IL-1 $\beta$ levels in SHR urine and eNOS levels in AngII-damaged human renal glomerular endothelial cells superfluid (113). San Cao decoction in network pharmacologic analysis may play a role in lowering blood pressure by regulating the PI3K-Akt-eNOS pathway (114).

Improvement of obesity-associated factors. Metabolic disorder is also an important cause of hypertensive nephropathy (115). Obesity plays a greater role than blood pressure in the progression of hypertensive kidney disease (116). Obesity itself is a risk factor for high blood pressure. And in obese patients, renal dysfunction and associated increased sodium reabsorption in renal tubules can lead to hypertension (117). The compression of perirenal fat on the kidneys results in the activation of RAS (117). Chronic obesity may gradually amplify hypertension, leading to resistance to antihypertensive treatment. (117). Insulin resistance leads to the constriction of the extruded arterioles, thus leading to high glomerular pressure, hyperperfusion and hyperfiltration $(118,119)$. These studies have demonstrated that obesity is closely associated with the incidence of hypertensive nephropathy. Herbal medicine has unique advantages in improving obesity. Astragaloside IV, as one of the main ingredients of Astragalus, is used to treat hypertension in high-fat diet-induced obese rats due to its anti-inflammatory effect and its ability to improve leptin resistance (71). Citrus paradisi and Ocimum sanctum infusions can decrease blood pressure and protect kidney function in obese rats (120).

A number of studies have shown that Chinese herbs can improve the effects of obesity on the kidneys of patients. Coptidis rhizoma can lower the blood lipid level and renal weight of fat-prone rats, and can improve urinary protein creatinine ratio and creatinine clearance rate in rats (121). The mechanism may be associated with the inhibition of the NLRP3 inflammasome (121). Through treatment of obesity-associated glomerulopathy in model rats with Tribulus terrestris L., it was found that the herb could decrease the body weight, blood pressure, serum cystatin $\mathrm{C}$ levels and migration of rats, as well as improve human endothelial cells migration, thus protecting renal function (80). Curcumin, as one of the most important components of turmeric, can improve body weight, abdominal fat index, urinary protein excretion and average glomerular diameter in mice, and can protect podocytes from leptin damage by blocking the Wnt/ $\beta$-catenin pathway (122). At the formula level, Mai Tong Fang inhibits fat generation and triglyceride accumulation in 3T3-L1 adipocytes (123).

\section{Model of hypertensive nephropathy in herbal medicine research}

In hypertensive nephropathy, herbal medicine has significant clinical efficacy in relieving proteinuria and controlling the progression of renal injury. However, the number of studies on the treatment of hypertensive nephropathy with Chinese herbal medicine is limited (Table SI). As aforementioned, certain compounds can control and alleviate diseases from multiple perspectives, and the Chinese herbs that contain such compounds have been listed. Subsequently, the present review tried to analyze the similarities of these plant medicines based on the theory of traditional Chinese medicine in an attempt to reach a conclusion. However, there are only few studies on this topic. Thus, the present review can only briefly discuss the summary of the application of herbal medicine in the basic research of hypertensive nephropathy.

In clinical research, the disease is often treated as one of the complications of hypertension, which has not received considerable attention. This is understandable, since the most effective way to control hypertensive nephropathy is to control blood pressure (124-126). Therefore, animal experimental models of hypertensive nephropathy are often used directly in hypertension models. Since hypertensive nephropathy is nephropathy caused by hypertension, modeling should ensure the presence of proteinuria without directly damaging the kidney. Therefore, the genetic hypertension model is the most common in such studies, while the renal hypertension model is the least desirable. Among these models, SHR was produced by inbreeding in Wistar rats with the highest blood pressure, and may progress to myocardial hypertrophy, heart failure, renal insufficiency and endothelium-dependent diastolic function impairment (127). Dahl salt-sensitive rats are SD rats on a high-salt diet (127). These rats showed myocardial hypertrophy, severe heart failure, hypertensive nephropathy, impaired endothelium-dependent diastolic function and other impairments (127-129). These animal models can reflect the pathogenesis of hypertensive nephropathy. Regarding cell models, previous studies have focused on endothelial cell injury, glomerular sclerosis and renal interstitial fibrosis (76). Therefore, the current common cell model involves the use of Ang II to interfere with endothelial cells and observe whether their function is abnormal, or to interfere with glomerular epithelial cells and renal tubular epithelial cells and observe whether they undergo EMT $(54,130,131)$. The pathogenesis of hypertensive nephropathy is not only caused by an abnormal RAS, but is the result of multiple mechanisms. The best model would be extracting the serum of hypertensive animals or patients to incubate cells (132). However, no such model has been reported in the studies on herbal medicine for hypertensive nephropathy thus far. In future experimental cell research, such a model should be developed, so as to better reconstruct the patients' disease.

\section{Discussion}

This review summarized three points. Firstly, the pathogenesis of hypertensive nephropathy was summarized. Secondly, herbal medicine studies based on these mechanisms were listed. Thirdly, the shortcomings of the current basic research on hypertensive nephropathy models and areas for improvement were discussed.

Hypertension nephropathy is a relatively complex mechanism of nephropathy. The basic pathogenesis of this disease includes renal hemodynamic changes and vascular remodeling, which are caused by various etiologies. At present, the treatment of hypertensive nephropathy in modern medicine is concentrated at a single site or approach, but the curative effect is not ideal. Different components of herbal medicine have obvious advantages in the treatment of hypertensive nephropathy. Previous studies on the efficacy and mechanism 
of herbal medicine in treating hypertensive nephropathy have suggested that herbal medicine plays an important role in improving renal perfusion, controlling vascular remodeling and delaying renal function progression. An interesting finding in these basic studies was that some herbs can act on two or three mechanisms at once. These experiments also provide evidence for the advantages of Chinese herbal medicine in the treatment of hypertensive nephropathy.

However, the clinical studies of herbal medicine on patients with hypertensive nephropathy are relatively scarce. Although basic research is essential in terms of the explanation of the mechanism, it is only used to observe the changes in a certain organ or even a certain type of cell, which makes the basic research itself somewhat static and one-sided, and it cannot observe the changes of patients dynamically and comprehensively as with clinical research. Therefore, basic research can only provide clues for the direction of clinical medicine, and cannot replace clinical research. Due to the lack of clinical data in this field, the content of this review has some limitations. In order to better promote traditional Chinese medicine, identify the efficacy of these herbs and explore their potential mechanisms, more clinical studies related to Chinese herbs are required in the future, as well as more well-designed, large-sample, long-term, randomized and controlled clinical trials to verify the efficacy and safety. With the in-depth study of herbal medicine, modern medicine will not only be able to treat hypertensive nephropathy, but also can make great progress in other disciplines.

\section{Acknowledgements}

Not applicable.

\section{Funding}

This study was supported by grants from the National Key Research and Development Project (grant no. 2019YFC1709402), National Natural Science Foundation of China (grant nos. 81673907 and 81973793 awarded to LB), Natural Science Foundation of Beijing Municipality (grant no. 7182070 awarded to LB) and Beijing Municipal Administration of Hospitals Clinical Medicine Development of special funding support (grant no. XLMX201833 awarded to LB).

\section{Availability of data and materials}

Not applicable.

\section{Authors' contributions}

BL, HD and ZF provided valuable suggestions and guidance for writing this manuscript. ZD was responsible for collecting the majority of the material to be reviewed and for writing this manuscript. WL, YG and FL collected the rest of the material to be reviewed. $\mathrm{ZZ}, \mathrm{NZ}$ and $\mathrm{XD}$ helped with writing the manuscript. QZ, XZ and JD were responsible for constructing Table 1. All authors read and approved the final manuscript.

\section{Ethics approval and consent to participate}

Not applicable.

\section{Patient consent for publication}

Not applicable.

\section{Competing interests}

The authors declare that they have no competing interests.

\section{References}

1. Seccia TM, Caroccia B and Calò LA: Hypertensive nephropathy. Moving from classic to emerging pathogenetic mechanisms. J Hypertens 35: 205-212, 2017.

2. Hart PD and Bakris GL: Hypertensive nephropathy: Prevention and treatment recommendations. Expert Opin Pharmacother 11: 2675-2686, 2010.

3. Damkjær M, Isaksson GL, Stubbe J, Jensen BL, Assersen K and Bie P: Renal renin secretion as regulator of body fluid homeostasis. Pflugers Arch 465: 153-165, 2013.

4. Huang QF, Hoshide S, Cheng HM, Park S, Park CG, Chen CH, Kario K and Wang JG; Characteristics On the Management of Hypertension in Asia-Morning Hypertension Discussion Group(COME Asia MHDG): Management of hypertension in patients with chronic kidney disease in Asia. Curr Hypertens Rev 12: 181-185, 2016.

5. Lu X and Crowley SD: Inflammation in salt-sensitive hypertension and renal damage. Curr Hypertens Rep 20: 103, 2018.

6. Guan Z, Makled MN and Inscho EW: Purinoceptors, renal microvascular function and hypertension. Physiol Res 69: 353-369, 2020.

7. Freedman BI and Cohen AH: Hypertension-attributed nephropathy: What's in a name? Nat Rev Nephrol 12: 27-36, 2016.

8. Kandasamy Y, Watson D and Rudd D: Biomarker of early glomerular injury in pre-eclampsia. Hypertens Pregnancy 34: 391-399, 2015.

9. Meier P: Atherosclerotic renal artery stenosis: Update on management strategies. Curr Opin Cardiol 26: 463-471, 2011.

10. Rodriguez-Iturbe B and Johnson RJ: The role of renal microvascular disease and interstitial inflammation in salt-sensitive hypertension. Hypertens Res 33: 975-980, 2010.

11. Textor SC and Lerman L: Renovascular hypertension and ischemic nephropathy. Am J Hypertens 23: 1159-1169, 2010.

12. Udani S, Lazich I and Bakris GL: Epidemiology of hypertensive kidney disease. Nat Rev Nephrol 7: 11-21, 2011.

13. Sun HJ: current opinion for hypertension in renal fibrosis. Adv Exp Med Biol 1165: 37-47, 2019.

14. Xie X, Atkins E, Lv J, Bennett A, Neal B, Ninomiya T, Woodward M, MacMahon S, Turnbull F, Hillis GS, et al: Effects of intensive blood pressure lowering on cardiovascular and renal outcomes: Updated systematic review and meta-analysis. Lancet 387: 435-443, 2016.

15. Romero CA and Carretero OA: Tubule-vascular feedback in renal autoregulation. Am J Physiol Renal Physiol 316: F1218-F1226, 2019.

16. Satou R, Shao W and Navar LG: Role of stimulated intrarenal angiotensinogen in hypertension. Ther Adv Cardiovasc Dis 9: 181-190, 2015.

17. Lau WL, Huisa BN and Fisher M: the cerebrovascular-chronic kidney disease connection: Perspectives and mechanisms. Transl Stroke Res 8: 67-76, 2017.

18. Ihm CG: Hypertension in chronic glomerulonephritis. Electrolyte Blood Press 13: 41-45, 2015.

19. Hughson MD, Puelles VG, Hoy WE, Douglas-Denton RN, Mott SA and Bertram JF: Hypertension, glomerular hypertrophy and nephrosclerosis: The effect of race. Nephrol Dial Transplant 29: 1399-1409, 2014.

20. D'Elia JA, Bayliss G, Gleason RE and Weinrauch LA: Cardiovascular-renal complications and the possible role of plasminogen activator inhibitor: A review. Clin Kidney J 9: 705-712, 2016.

21. Simeoni M, Armeni A, Summaria C, Cerantonio A and Fuiano G: Current evidence on the use of anti-RAAS agents in congenital or acquired solitary kidney. Ren Fail 39: 660-670, 2017.

22. Campese VM, Mitra N and Sandee D: Hypertension in renal parenchymal disease: Why is it so resistant to treatment? Kidney Int 69: 967-973, 2006. 
23. Heyman SN, Khamaisi M, Rosen S and Rosenberger C: Renal parenchymal hypoxia, hypoxia response and the progression of chronic kidney disease. Am J Nephrol 28: 998-1006, 2008.

24. Lerman LO, Textor SC and Grande JP: Mechanisms of tissue injury in renal artery stenosis: Ischemia and beyond. Prog Cardiovasc Dis 52: 196-203, 2009.

25. Zeng Y, Wang X, Xie F and Zheng Z: Ischemia-induced glomerular parietal epithelial cells hyperplasia: Commonly misdiagnosed cellular crescent in renal biopsy. Pathol Res Pract 213: 982-986, 2017.

26. Nicolosi PA, Tombetti E, Maugeri N, Rovere-Querini P, Brunelli S and Manfredi AA: Vascular remodelling and mesenchymal transition in systemic sclerosis. Stem Cells Int 2016 $4636859,2016$.

27. Rodriguez-Iturbe B, Pons H and Johnson RJ: Role of the immune system in hypertension. Physiol Rev 97: 1127-1164, 2017.

28. Frame AA and Wainford RD: Mechanisms of altered renal sodium handling in age-related hypertension. Am J Physiol Renal Physiol 315: F1-F6, 2018.

29. Zhang C, Booz GW, Yu Q, He X, Wang S and Fan F: Conflicting roles of 20-HETE in hypertension and renal end organ damage. Eur J Pharmacol 833: 190-200, 2018.

30. Mendoza-Torres E, Oyarzún A, Mondaca-Ruff D, Azocar A, Castro PF, Jalil JE, Chiong M, Lavandero S and Ocaranza MP: ACE2 and vasoactive peptides: Novel players in cardiovascular/renal remodeling and hypertension. Ther Adv Cardiovasc Dis 9: 217-237, 2015.

31. Laurent $S$ and Boutouyrie P: The structural factor of hypertension: Large and small artery alterations. Circ Res 116: 1007-1021, 2015.

32. Miyagawa K and Emoto N: Current state of endothelin receptor antagonism in hypertension and pulmonary hypertension. Ther Adv Cardiovasc Dis 8: 202-216, 2014.

33. Povlsen AL, Grimm D, Wehland $M$, Infanger $M$ and Krüger $M$ : The vasoactive mas receptor in essential hypertension. J Clin Med 9: 267, 2020

34. Tracy RE: Renal vasculature in essential hypertension: A review of some contrarian evidence. Contrib Nephrol 169: 327-336, 2011.

35. Brown IAM, Diederich L, Good ME, DeLalio LJ, Murphy SA, Cortese-Krott MM, Hall JL, Le TH and Isakson BE: Vascula smooth muscle remodeling in conductive and resistance arteries in hypertension. Arterioscler Thromb Vasc Biol 38: 1969-1985, 2018.

36. Li Q, Youn JY and Cai H: Mechanisms and consequences of endothelial nitric oxide synthase dysfunction in hypertension. J Hypertens 33: 1128-1136, 2015.

37. Xu M, Lu YP, Hasan AA and Hocher B: Plasma ET-1 concentrations are elevated in patients with hypertension-meta-analysis of clinical studies. Kidney Blood Press Res 42: 304-313, 2017.

38. Versmissen J, Mirabito Colafella KM, Koolen SLW and Danser AHJ: Vascular cardio-oncology: Vascular endothelial growth factor inhibitors and hypertension. Cardiovasc Res 115: 904-914, 2019

39. Wu J, Agbor LN, Fang S, Mukohda M, Nair AR, Nakagawa P, Sharma A, Morgan DA, Grobe JL, Rahmouni K, et al: Failure to vasodilate in response to salt loading blunts renal blood flow and causes salt-sensitive hypertension. Cardiovasc Res 117: 308-319, 2021.

40. Hill GS: Hypertensive nephrosclerosis. Curr Opin Nephrol Hypertens 17: 266-270, 2008.

41. Zhang L, Yang L, Shergis J, Zhang L, Zhang AL, Guo X, Qin X, Johnson D, Liu X, Lu C, et al: Chinese herbal medicine for diabetic kidney disease: A systematic review and meta-analysis of randomised placebo-controlled trials. BMJ Open 9: e025653, 2019.

42. Ren W, Liao J, Chen J, Li Z and Huang L: The effect of Chinese herbal medicine combined with western medicine on vascular endothelial function for patients with hypertension: Protocol for a systematic review and meta-analysis. Medicine (Baltimore) 98 : e18134, 2019

43. Wang J, Qin T, Chen J, Li Y, Wang L, Huang $\mathrm{H}$ and Li J: Hyperuricemia and risk of incident hypertension: A systematic review and meta-analysis of observational studies. PLoS One 9: e114259, 2014

44. Gao X, Peleli M, Zollbrecht C, Patzak A, Persson AE and Carlström M: Adenosine A1 receptor-dependent and independent pathways in modulating renal vascular responses to angiotensin II. Acta Physiol (Oxf) 213: 268-276, 2015.
45. Pojoga LH, Yao TM, Opsasnick LA, Siddiqui WT, Reslan OM, Adler GK, Williams GH and Khalil RA: Cooperative role of mineralocorticoid receptor and caveolin-1 in regulating the vascular response to low nitric oxide-high angiotensin II-induced cardiovascular injury. J Pharmacol Exp Ther 355: 32-47, 2015.

46. Yu D, Shi M, Bao J, Yu X, Li Y and Liu W: Genipin ameliorates hypertension-induced renal damage via the angiotensin II-TLR/MyD88/MAPK pathway. Fitoterapia 112: 244-253, 2016.

47. Zhang SF, Mao XJ, Jiang WM and Fang ZY: Qian Yang Yu Yin Granule protects against hypertension-induced renal injury by epigeneticmechanismlinked tonicotinamide $\mathrm{N}$-methyltransferase (NNMT) expression. J Ethnopharmacol 255: 112738, 2020.

48. Han L, Ma Y, Qin JG, Li LN, Gao YS, Zhang XY, Guo Y, Song LM, Luo YN and Chi XY: The renal protective effect of Jiangya tongluo formula, through regulation of adrenomedullin and angiotensin II, in rats with hypertensive nephrosclerosis. Evid Based Complement Alternat Med 2015: 428106, 2015.

49. Tian D, Ling S, Chen G, Li Y, Liu J, Ferid M and Bian K: Hypertensive nephropathy treatment by heart-protecting musk pill: A study of anti-inflammatory therapy for target organ damage of hypertension. Int J Gen Med 4: 131-139, 2011.

50. Chen YH, Lei SS, Li B, Luo R, He X, Wang YZ, Zhou FC, Lv GY and Chen SH: Systematic understanding of the mechanisms of flos chrysanthemi indici-mediated effects on hypertension via computational target fishing. Comb Chem High Throughput Screen 23: 92-110, 2020.

51. Limón RI, Peñas E, Martínez-Villaluenga $C$ and Frias J: Role of elicitation on the health-promoting properties of kidney bean sprouts. LWT Food Sci Technol 56: 328-334, 2014.

52. Chen H, Wang MC, Chen YY, Chen L, Wang YN, Vaziri ND, Miao H and Zhao YY: Alisol B 23-acetate attenuates CKD progression by regulating the renin-angiotensin system and gut-kidney axis. Ther Adv Chronic Dis 11: 2040622320920025 , 2020.

53. Chen L, Chen DQ, Wang M, Liu D, Chen H, Dou F, Vaziri ND and Zhao YY: Role of RAS/Wnt/ $\beta$-catenin axis activation in the pathogenesis of podocyte injury and tubulo-interstitial nephropathy. Chem Biol Interact 273: 56-72, 2017.

54. Wang M, Chen DQ, Wang MC, Chen H, Chen L, Liu D, Zhao H and Zhao YY: Poricoic acid ZA, a novel RAS inhibitor, attenuates tubulo-interstitial fibrosis and podocyte injury by inhibiting TGF- $\beta$ /Smad signaling pathway. Phytomedicine 36: 243-253, 2017.

55. Wang $M$, Chen DQ, Chen L, Liu D, Zhao $H$, Zhang ZH, Vaziri ND, Guo Y, Zhao YY and Cao G: Novel RAS inhibitors poricoic acid ZG and poricoic acid ZH attenuate renal fibrosis via a Wnt/3-catenin pathway and targeted phosphorylation of Smad3 signaling. J Agric Food Chem 66: 1828-1842, 2018.

56. Wang M, Chen DQ, Chen L, Cao G, Zhao H, Liu D, Vaziri ND, Guo Y and Zhao YY: Novel inhibitors of the cellular renin-angiotensin system components, poricoic acids, target Smad3 phosphorylation and Wnt/ $\beta$-catenin pathway against renal fibrosis. Br J Pharmacol 175: 2689-2708, 2018.

57. Chen $\mathrm{H}$, Yang T, Wang MC, Chen DQ, Yang $\mathrm{Y}$ and Zhao $\mathrm{YY}$ : Novel RAS inhibitor 25-O-methylalisol F attenuates epithelial-to-mesenchymal transition and tubulo-interstitial fibrosis by selectively inhibiting TGF- $\beta$-mediated Smad 3 phosphorylation. Phytomedicine 42: 207-218, 2018.

58. Zhang CC, Gu WL, Wu XM, Li YM, Chen CX and Huang XY: Active components from Radix scrophulariae inhibits the ventricular remodeling induced by hypertension in rats. Springerplus 5: 358, 2016.

59. Lian FZ, Cheng P, Ruan CS, Ling XX, Wang XY, Pan M, Chen ML, Shen AZ and Gao S: Xin-Ji-Er-Kang ameliorates kidney injury following myocardial infarction by inhibiting oxidative stress via Nrf2/HO-1 pathway in rats. Biomed Pharmacother 117: 109124, 2019.

60. Yang T, Chen YY, Liu JR, Zhao H, Vaziri ND, Guo Y and Zhao YY: Natural products against renin-angiotensin system for antifibrosis therapy. Eur J Med Chem 179: 623-633, 2019.

61. Deng YF, Aluko RE, Jin Q, Zhang Y and Yuan LJ: Inhibitory activities of baicalin against renin and angiotensin-converting enzyme. Pharm Biol 50: 401-406, 2012.

62. Lv GY, Zhang YP, Gao JL, Yu JJ, Lei J, Zhang ZR, Li B, Zhan RJ and Chen SH: Combined antihypertensive effect of luteolin and buddleoside enriched extracts in spontaneously hypertensive rats. J Ethnopharmacol 150: 507-513, 2013.

63. Zhao YY, Li HT, Feng YL, Bai X and Lin RC: Urinary metabonomic study of the surface layer of Poria $\operatorname{cocos}$ as an effective treatment for chronic renal injury in rats. J Ethnopharmacol 148 : 403-410, 2013. 
64.Zheng X, Wang S, Zou X, Jing Y, Yang R, Li S and Wang F: Ginsenoside Rb1 improves cardiac function and remodeling in heart failure. Exp Anim 66: 217-228, 2017.

65. Kaiser S, Carvalho ÂR, Pittol V, Dietrich F, Manica F, Machado MM, de Oliveira LF, Oliveira Battastini AM and Ortega GG: Genotoxicity and cytotoxicity of oxindole alkaloids from Uncaria tomentosa (cat's claw): Chemotype relevance. J Ethnopharmacol 189: 90-98, 2016.

66. Zhang RH, Liu ZK, Yang DS, Zhang XJ, Sun HD and Xiao WL: Phytochemistry and pharmacology of the genus leonurus: The herb to benefit the mothers and more. Phytochemistry 147: $167-183,2018$

67. Rossi GP, Seccia TM, Barton M, Danser AHJ, de Leeuw PW, Dhaun N, Rizzoni D, Rossignol P, Ruilope LM, van den Meiracker AH, et al: Endothelial factors in the pathogenesis and treatment of chronic kidney disease part I: General mechanisms: A joint consensus statement from the European society of hypertension working group on endothelin and endothelial factors and the Japanese society of hypertension. J Hypertens 36: 451-461, 2018.

68. Brusilovskaya K, Königshofer P, Schwabl P and Reiberger T: Vascular targets for the treatment of portal hypertension. Semin Liver Dis 39: 483-501, 2019.

69. Westfall TC, Macarthur H, Byku M, Yang CL and Murray J: Interactions of neuropeptide $\mathrm{y}$, catecholamines, and angiotensin at the vascular neuroeffector junction. Adv Pharmacol 68: $115-139,2013$

70. Zhu X, Zhou Z, Zhang Q, Cai W, Zhou Y, Sun H and Qiu L: Vaccarin administration ameliorates hypertension and cardiovascular remodeling in renovascular hypertensive rats. J Cell Biochem 119: 926-937, 2018.

71. Jiang P, Ma D, Wang X, Wang Y, Bi Y, Yang J, Wang X and Li X: Astragaloside IV prevents obesity-associated hypertension by improving pro-inflammatory reaction and leptin resistance. Mol Cells 41: 244-255, 2018.

72. Wang YC, Ma DF, Jiang P, Zhang YM, Zhou GF, Yang JL, Li ZY and Li X: Guizhi decoction () inhibits cholinergic transdifferentiation by regulating imbalance of NGF and LIF in salt-sensitive hypertensive heart failure rats. Chin J Integr Med 26: 188-196, 2020.

73. Xiong W, He FF, You RY, Xiong J, Wang YM, Zhang C, Meng XF and $\mathrm{Su} \mathrm{H}$ : Acupuncture application in chronic kidney disease and its potential mechanisms. Am J Chin Med 46: 1169-1185, 2018.

74. Paterno JC, Bergamaschi CT, Campos RR, Higa EM, Soares MF, Schor N, Freire AO and Teixeira VP: Electroacupuncture and moxibustion decrease renal sympathetic nerve activity and retard progression of renal disease in rats. Kidney Blood Press Res 35: 355-364, 2012.

75. Yang JW, Ye Y, Wang XR, Li F, Xiao LY, Shi GX and Liu CZ: Acupuncture attenuates renal sympathetic activity and blood pressure via beta-adrenergic receptors in spontaneously hypertensive rats. Neural Plast 2017: 8696402, 2017.

76. Mennuni S, Rubattu S, Pierelli G, Tocci G, Fofi C and Volpe M: Hypertension and kidneys: Unraveling complex molecular mechanisms underlying hypertensive renal damage. J Hum Hypertens 28: 74-79, 2014

77. Crowley SD: The cooperative roles of inflammation and oxidative stress in the pathogenesis of hypertension. Antioxid Redox Signal 20: 102-120, 2014.

78. Zhang J, An SJ, Fu JQ, Liu P, Shao TM, Li M, Li X, Jiao Z and Chai XQ: Mixed aqueous extract of Salvia miltiorrhiza reduces blood pressure through inhibition of vascular remodelling and oxidative stress in spontaneously hypertensive rats. Cell Physiol Biochem 40: 347-360, 2016

79. Li Y, Huang C, Fu W, Zhang H, Lao Y, Zhou H, Tan $\mathrm{H}$ and $\mathrm{Xu} \mathrm{H}$ Screening of the active fractions from the Coreopsis tinctoria nutt. Flower on diabetic endothelial protection and determination of the underlying mechanism. J Ethnopharmacol 253 112645,2020

80. Teles F, da Silva TM, da Cruz Júnior FP, Honorato VH, de Oliveira Costa H, Barbosa AP, de Oliveira SG, Porfírio Z, Libório AB, Borges RL and Fanelli C: Brazilian red propolis attenuates hypertension and renal damage in $5 / 6$ renal ablation model. PLoS One 10: e0116535, 2015.

81. Guo H, Kuang Z, Zhang J, Zhao X, Pu P and Yan J: The preventive effect of Apocynum venetum polyphenols on D-galactose-induced oxidative stress in mice. Exp Ther Med 19: $557-568,2020$.
82. Moodley K, Naidoo Y and Mackraj I: Effects of Tulbaghia violacea Harv. (Alliaceae) rhizome methanolic extract on kidney function and morphology in Dahl salt-sensitive rats. J Ethnopharmacol 155: 1194-1203, 2014.

83. Hamza SM and Dyck JR: Systemic and renal oxidative stress in the pathogenesis of hypertension: Modulation of long-term control of arterial blood pressure by resveratrol. Front Physiol 5: $292,2014$.

84.Zhu J, Zhang Y and Yang C: Protective effect of 3-n-butylphthalide against hypertensive nephropathy in spontaneously hypertensive rats. Mol Med Rep 11: 1448-1454, 2015.

85. Lin F, Huang X, Xing F, Xu L, Zhang W, Chen Z, Ke X, Song Y and Zeng Z: Semen brassicae reduces thoracic aortic remodeling, inflammation, and oxidative damage in spontaneously hypertensive rats. Biomed Pharmacother 129: 110400, 2020.

86. Gai Z, Wang Z, Zhang L, Ma J and Zhu Q: Paeonol protects against hypertension in spontaneously hypertensive rats by restoring vascular endothelium. Biosci Biotechnol Biochem 83: 1992-1999, 2019.

87. Lu H, Yao H, Zou R, Chen X and Xu H: Galangin suppresses renal inflammation via the inhibition of NF- $\mathrm{BB}, \mathrm{PI} 3 \mathrm{~K} / \mathrm{AKT}$ and NLRP3 in uric acid treated NRK-52E tubular epithelial cells. Biomed Res Int 2019: 3018357, 2019.

88. Dong H, Ming S, Fang J, Li Y and Liu L: Icariin ameliorates angiotensin II-induced cerebrovascular remodeling by inhibiting Nox2-containing NADPH oxidase activation. Hum Cell 32: 22-30, 2019.

89. Yan D, Yue B, Qian M, Zhao L, Zhang Z, Qian H, Yan S, Qian Y and Fang Z: JYYS granule mitigates renal injury in clinic and in spontaneously hypertensive rats by inhibiting $\mathrm{NF}-\kappa \mathrm{B}$ signaling-mediated microinflammation. Evid Based Complement Alternat Med 2018: 8472963, 2018.

90. Luo WM, Kong J, Gong Y, Liu XQ, Yang RX and Zhao YX: Tongxinluo protects against hypertensive kidney injury in spontaneously-hypertensive rats by inhibiting oxidative stress and activating forkhead box o1 signaling. PLoS One 10: e0145130, 2015.

91. Jiang J, Huang D, Li Y, Gan Z, Li H, Li X, Bian K and Ke Y: Heart protection by herb formula BanXia BaiZhu TianMa decoction in spontaneously hypertensive rats. Evid Based Complement Alternat Med 2019: 5612929, 2019.

92. Ding K, Wang Y, Jiang W, Zhang Y, Yin H and Fang Z: Qian Yang $\mathrm{Yu}$ Yin Granule-containing serum inhibits angiotensin II-induced proliferation, reactive oxygen species production, and inflammation in human mesangial cells via an NADPH oxidase 4-dependent pathway. BMC Complement Altern Med 15: 81, 2015.

93. Lu L, Sun X, Chen C, Qin Y and Guo X: Shexiang baoxin pill, derived from the traditional Chinese medicine, provides protective roles against cardiovascular diseases. Front Pharmacol 9: 1161,2018

94. Wang XY, Huang GY, Lian FZ, Pan M, Ruan CS, Ling XX, Chen ML, Shen AZ and Gao S: Protective effect of Xin-Ji-Er-Kang on cardiovascular remodeling in high-salt induced hypertensive mice: Role ofoxidative stress and endothelial dysfunction. Biomed Pharmacother 115: 108937, 2019.

95. Guo K, Lan CZ, Yu TT, Huang LL, Wang XH, Pan C and Gao S: Effects of Xin-Ji-Er-Kang formula on 2K1C-induced hypertension and cardiovascular remodeling in rats. J Ethnopharmacol 155: 1227-1235, 2014

96. Yu TT, Guo K, Chen HC, Lan CZ, Wang J, Huang LL, Wang XH, Zhang Z and Gao S: Effects of traditional Chinese medicine Xin-Ji-Er-Kang formula on $2 \mathrm{~K} 1 \mathrm{C}$ hypertensive rats: Role of oxidative stress and endothelial dysfunction. BMC Complement Altern Med 13: 173, 2013.

97. Liu W, Lin S, Cai Q, Zhang L, Shen A, Chen Y and Peng J: Qingxuan Jiangya decoction mitigates renal interstitial fibrosis in spontaneously hypertensive rats by regulating transforming growth factor- $\beta 1 /$ Smad signaling pathway. Evid Based Complement Alternat Med 2017: 1576328, 2017.

98. Qin T, Wu L, Hua Q, Song Z, Pan Y and Liu T: Prediction of the mechanisms of action of Shenkang in chronic kidney disease: A network pharmacology study and experimental validation. J Ethnopharmacol 246: 112128, 2020.

99. Tian XL and Li Y: Endothelial cell senescence and age-related vascular diseases. J Genet Genomics 41: 485-495, 2014

100. Regina C, Panatta E, Candi E, Melino G, Amelio I, Balistreri CR, Annicchiarico-Petruzzelli M, Di Daniele N and Ruvolo G: Vascular ageing and endothelial cell senescence: Molecular mechanisms of physiology and diseases. Mech Ageing Dev 159: $14-21,2016$ 
101. Lankhorst S, Kappers MH, van Esch JH, Danser AH and van den Meiracker AH: Hypertension during vascular endothelial growth factor inhibition: Focus on nitric oxide, endothelin-1, and oxidative stress. Antioxid Redox Signal 20: 135-145, 2014.

102. Yang X, Shao H, Chen Y, Ding N, Yang A, Tian J, Jiang Y, $\mathrm{Li} \mathrm{G}$ and Jiang Y: In renal hypertension, Cirsium japonicum strengthens cardiac function via the intermedin/nitric oxide pathway. Biomed Pharmacother 101: 787-791, 2018.

103. Yoshitomi H, Zhou J, Nishigaki T, Li W, Liu T, Wu L and Gao M: Morinda citrifolia (Noni) fruit juice promotes vascular endothelium function in hypertension via glucagon-like peptide-1 receptor-CaMKK $\beta$-AMPK-eNOS pathway. Phytother Res 34: 2341-2350, 2020.

104. Razali N, Dewa A, Asmawi MZ, Mohamed N and Manshor NM: Mechanisms underlying the vascular relaxation activities of Zingiber officinale var. rubrum in thoracic aorta of spontaneously hypertensive rats. J Integr Med 18: 46-58, 2020.

105. Akinyemi AJ, Onyebueke N, Faboya OA, Onikanni SA, Fadaka A and Olayide I: Curcumin inhibits adenosine deaminase and arginase activities in cadmium-induced renal toxicity in rat kidney. J Food Drug Anal 25: 438-446, 2017.

106.Zhang DM, Li YC, Xu D, Ding XQ and Kong LD: Protection of curcumin against fructose-induced hyperuricaemia and renal endothelial dysfunction involves NO-mediated JAK-STAT signalling in rats. Food Chem 134: 2184-2193, 2012.

107. Tew WY, Tan CS, Asmawi MZ and Yam MF: Underlying mechanism of vasorelaxant effect exerted by 3,5,7,2',4'-pentahydroxyflavone in rats aortic ring. Eur J Pharmacol 880: 173123, 2020.

108. Yang J, Wang R, Cheng X, Qu H, Qi J, Li D, Xing Y, Bai $Y$ and Zheng $X$ : The vascular dilatation induced by Hydroxysafflor yellow A (HSYA) on rat mesenteric artery through TRPV4-dependent calcium influx in endothelial cells. J Ethnopharmacol 256: 112790, 2020.

109. Xu J, Zhang C, Shi X, Li J, Liu M, Jiang W and Fang Z: Efficacy and safety of sodium tanshinone IIA sulfonate injection on hypertensive nephropathy: A systematic review and meta-analysis. Front Pharmacol 10: 1542, 2019.

110. Li P, Peng Y, Ma Q, Li Z and Zhang X: Study on the formation of antihypertensive twin drugs by caffeic acid and ferulic acid with telmisartan. Drug Des Devel Ther 14: 977-992, 2020

111. He F, Chu JF, Chen HW, Lin W, Lin S, Chen YQ, Peng J and Chen KJ: Qingxuan Jiangya decoction () prevents blood pressure elevation and ameliorates vascular structural remodeling via modulating TGF- $\beta 1 /$ Smad pathway in spontaneously hypertensive rats. Chin J Integr Med 26: 180-187, 2020

112. Ye F, He J, Wu X, Xie J, Chen H, Tang X, Lai Z, Huang R and Huang J: The regulatory mechanisms of Yulangsan MHBFC reversing cardiac remodeling in rats based on eNOS-NO signaling pathway. Biomed Pharmacother 117: 109141, 2019.

113. Li W, Jiang YH, Wang Y, Zhao M, Hou GJ, Hu HZ and Zhou L: Protective effects of combination of radix astragali and radix salviae miltiorrhizae on kidney of spontaneously hypertensive rats and renal intrinsic cells. Chin J Integr Med 26: 46-53, 2020

114. Ma C, Zhai C, Xu T, Lu F, Zhang S, Li C, Wang Q, Cheng F and Wang X: A systems pharmacology-based study of the molecular mechanisms of San Cao decoction for treating hypertension. Evid Based Complement Alternat Med 2019: 3171420, 2019.

115. Tanaka $\mathrm{M}$ and Itoh $\mathrm{H}$ : Hypertension as a metabolic disorder and the novel role of the gut. Curr Hypertens Rep 21: 63, 2019.

116. Hall JE, do Carmo JM, da Silva AA, Wang Z and Hall ME: Obesity, kidney dysfunction and hypertension: Mechanistic links. Nat Rev Nephrol 15: 367-385, 2019.

117. Bell DS: Treatment of diabetic hypertension. Diabetes Obes Metab 11: 433-444, 2009.

118. Busija DW, Miller AW, Katakam P and Erdös B: Insulin resistance and associated dysfunction of resistance vessels and arterial hypertension. Minerva Med 96: 223-232, 2005.
119. Eringa EC, Bakker W and van Hinsbergh VW: Paracrine regulation of vascular tone, inflammation and insulin sensitivity by perivascular adipose tissue. Vascul Pharmacol 56: 204-209, 2012.

120. Gamboa-Gómez C, Pérez-Ramírez IF, González-Gallardo A Gallegos-Corona MA, Ibarra-Alvarado C and ReynosoCamacho R: Effect of Citrus paradisi and Ocimum sanctum infusions on blood pressure regulation and its association with renal alterations in obese rats. J Food Biochem 40: 345-357, 2016.

121. Ren Y, Wang D, Lu F, Zou X, Xu L, Wang K, Huang W, Su H, Zhang C, Gao Y and Dong H: Coptidis rhizoma inhibits NLRP3 inflammasome activation and alleviates renal damage in early obesity-related glomerulopathy. Phytomedicine 49: 52-65, 2018.

122. Liu BL, Chen YP, Cheng H, Wang YY, Rui HL, Yang M, Dong HR, Han DN and Dong J: The protective effects of curcumin on obesity-related glomerulopathy are associated with inhibition of $\mathrm{Wnt} / \beta$-catenin signaling activation in podocytes. Evid Based Complement Alternat Med 2015: 827472, 2015.

123. Ma L, Huang L, Pei H, Liu Z, Xie C, Lei L, Chen X, Ye H, Peng A and Chen L: Pharmacological effects of the water fraction of key components in the traditional Chinese prescription Mai Tong Fang on 3T3-L1 adipocytes and ob/ob diabetic mice. Molecules 19: 14687-14698, 2014.

124. Basile J and Toth P: Angiotensin receptor blockers: Role in hypertension management, cardiovascular risk reduction, and nephropathy. South Med J 102 (10 Suppl): S1-S12, 2009.

125. Pirkle JL and Freedman BI: Hypertension and chronic kidney disease: Controversies in pathogenesis and treatment. Minerva Urol Nefrol 65: 37-50, 2013

126. Yang C, Wang H, Zhao X, Matsushita K, Coresh J, Zhang L and Zhao MH: CKD in China: Evolving spectrum and public health implications. Am J Kidney Dis 76: 258-264, 2020.

127. Leong XF, Ng CY and Jaarin K: Animal models in cardiovascular research: Hypertension and atherosclerosis. Biomed Res Int 2015: 528757, 2015.

128. Meili-Butz S, Bühler K, John D, Buser P, Vale WW, Peterson KL, Brink $M$ and Dieterle T: Acute effects of urocortin 2 on cardiac function and propensity for arrhythmias in an animal model of hypertension-induced left ventricular hypertrophy and heart failure. Eur J Heart Fail 12: 797-804, 2010.

129. Liu ML, Song HX, Tian XX, Liu YX, Liu D, Hou ZW, Li JY, Yan $\mathrm{CH}$ and Han YL: Recombinant cellular repressor of E1A-stimulated genes protects against renal fibrosis in Dahl salt-sensitive rats. Am J Nephrol 51: 401-410, 2020.

130. Lu Q, Ma Z, Ding Y, Bedarida T, Chen L, Xie Z, Song P and Zou MH: Circulating miR-103a-3p contributes to angiotensin II-induced renal inflammation and fibrosis via a SNRK/NF- $\mathrm{KB} / \mathrm{p} 65$ regulatory axis. Nat Commun 10: 2145, 2019.

131. Han WQ, Xu L, Tang XF, Chen WD, Wu YJ and Gao PJ: Membrane rafts-redox signalling pathway contributes to renal fibrosis via modulation of the renal tubular epithelial-mesenchymal transition. J Physiol 596: 3603-3616, 2018.

132. Su Y, Deng X, Ma R, Dong Z, Wang F and Shi J: The Exposure of phosphatidylserine influences procoagulant activity in retinal vein occlusion by microparticles, blood cells, and endothelium. Oxid Med Cell Longev 2018: 3658476, 2018.

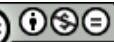

This work is licensed under a Creative Commons Attribution-NonCommercial-NoDerivatives 4.0 International (CC BY-NC-ND 4.0) License. 